\title{
COVID-19 and missed routine immunizations: designing for effective catch-up in Canada
}

\author{
Noni E. MacDonald ${ }^{1,2}$ (D) Jeannette L. Comeau ${ }^{1,2} \cdot$ Ève Dubé $^{3,4} \cdot$ Lucie M. Bucci $^{5}$ \\ Received: 29 May 2020 / Accepted: 8 July 2020 / Published online: 6 August 2020 \\ (C) The Canadian Public Health Association 2020
}

\begin{abstract}
COVID-19 has led to disruption in routine immunization programs around the globe and here in Canada. The National Advisory Committee on Immunization (NACI) in Canada has indicated that this sets the stage for serious outbreaks of vaccine-preventable diseases. The World Health Organization has evidence-based guidance on how to address missed opportunities for vaccination, albeit predominately applicable for low- and middle-income countries. In Canada, immunization applies beyond infant and childhood immunization, with immunization across the life course being recommended by NACI. Three components stand out and must be integrated and used concurrently for best effect on catch-up in Canada: (1) Identify who has been missed across the life course; (2) detect delivery gaps, adapt and adjust, and develop multipronged tailored strategies for catch-up; and (3) communicate, document, evaluate and readjust the immunization programs. All must be adapted to the reality of the evolving COVID-19 pandemic. We cannot go back to a pre-COVID-19 world. However, ensuring that routine immunization and catch-up programs are done well during this pandemic strengthens the immunization foundation in Canada for when COVID-19 vaccines become available.
\end{abstract}

\section{Résumé}

La pandémie de la COVID-19 a perturbé les programmes de vaccination systématique autour du monde et ici au Canada. Le Comité Consultatif National sur l'Immunisation (CCNI) au Canada a indiqué que ces perturbations pourraient entraîner des éclosions sévères de maladies évitables par la vaccination. L'Organisation Mondiale de la Santé a émis des recommandations fondées sur des données probantes afin de diminuer les occasions manquées de vaccination, ces recommandations s'appliquant toutefois principalement aux pays en voie de développement. Au Canada, la vaccination vise tous les groupes d'âge et non seulement les nourrissons et les enfants, la vaccination tout au long du cycle de la vie étant recommandée par le CCNI. Trois éléments doivent être mis de l'avant, intégrés et utilisés de façon concomitante afin d'optimiser le rattrapage de la vaccination au Canada : 1) identifier quelles sont les personnes qui n'ont pas reçu les vaccins recommandés à travers tous les groupes d'âge; 2) adapter l'organisation des services de vaccination, détecter les enjeux et développer des interventions à composantes multiples pour optimiser le rattrapage; et 3) communiquer, décrire, évaluer et réajuster les programmes de vaccination. Tout doit être adapté pour s'ajuster à la réalité d'une pandémie de la COVID-19 en constante évolution. Nous ne pouvons pas retourner à un monde « pré-COVID-19». Toutefois, nous assurant que les programmes de vaccination systématique et de rattrapage sont bien exécutés durant cette pandémie renforcera les fondements de la vaccination au Canada afin de nous rendre prêts lorsque les vaccins contre la COVID-19 seront disponibles.

Keywords Routine immunization · Immunization catch-up programs · COVID-19

Mots-clés Vaccination systématique · programme de rattrapage de vaccination · COVID-19

Noni E. MacDonald

noni.macdonald@dal.ca

1 Department of Pediatrics, Dalhousie University, Halifax, Nova Scotia, Canada

2 IWK Health Centre, Halifax, Nova Scotia, Canada
3 Institut National de Santé Publique du Québec, Québec City, Québec, Canada

4 Université Laval, Québec City, Québec, Canada

5 Immunize Canada, Canadian Public Health Association, Ottawa Ontario, Canada 
The COVID-19 pandemic is a multifaceted villain causing major morbidity and mortality as well as negatively impacting our healthcare systems, our economies and even how we live our lives. COVID-19 has also led to disruption in routine immunization programs, including decreases in timely infant and childhood immunization globally (World Health Organization 2020) and in Canada and the United States (Santoli et al. 2020). As the National Advisory Committee on Immunization (NACI) in Canada has noted, this sets the stage for serious outbreaks of vaccine-preventable diseases (VPD) (National Advisory Committee on Immunization 2020). For low- and middle-income countries (LMIC), the negative impact is stark. Mathematical modelling from the London School of Hygiene and Tropical Medicine suggests that for each excess COVID-19 death due to an infection acquired during the vaccination visit (predominantly among elderly household members), around 29 to 347 future child deaths could be prevented with sustained routine immunization (Abbas et al. 2020).

\section{Recognizing the COVID-19-related missed routine immunization problem, what can be done in Canada?}

The World Health Organization (WHO) has evidence-based guidance on how to address missed opportunities for vaccination, albeit predominately applicable for LMIC (https://www. who.int/immunization/programmes_systems/policies strategies/MOV/en/). Although revised in 2017, well before the COVID-19 pandemic, there is much that is useful in the formal 10-step process for consideration in Canadian catch-up programs.

Specifically, three components stand out and must be integrated and used concurrently for best effect.

\section{Identify who has been missed}

Identifying unimmunized and under-immunized individuals is not simple in Canada because we do not have fully integrated patient-centred health information systems that include vital statistic links to births and deaths. Immunization registries, while helpful, better count who has been immunized in their locale rather than detecting those missed. Furthermore, such registries may not include those who have recently moved to Canada or migrated internally from another province or territory. Patients at high risk of VPD as a consequence of other medical problems such as recent splenectomy are not included. Bearing in mind that all data must be held confidentially to ensure privacy, data triangulation (Edelstein et al. 2019) using public health and school registries (new arrivals to an area; those in specific grades), as well as physician, clinic, pharmacy and hospital records, can help to optimize finding those who require catch-up.

Additional efforts must be made to actively search out those missing from the collected data. Public health messages raising awareness of the importance of routine immunization across the life course for the health and well-being of all, noting why this is important even during this COVID-19 pandemic and who is especially vulnerable to VPDs, may help draw forward more names to add to catch-up lists. These lists need to extend beyond infants and young children to everyone across the life course. This recommended immunization across the life course concept may not be familiar to many (https://www.canada.ca/en/publichealth/services/vaccination-adults.html). Communities must be encouraged to step up to promote and support immunization in order to encourage catch-up, thereby preventing VPD outbreaks that would add further pressure on public health and healthcare systems already stressed by COVID-19.

Control of COVID-19 will ultimately rest on developing high levels of community immunity achieved through immunization. The skills and tools used to develop routine immunization catch-up lists will be very helpful for developing COVID-19 vaccine missed immunization lists when the vaccine(s) become widely available.

\section{Detect delivery gaps, adapt and adjust, and develop multipronged tailored strategies for catch-up}

Given that there is no pre-COVID-19 world to go back to, now is the time to determine how to go forward more effectively. Routine immunization programs need to be reinforced while ensuring physical distancing and other measures for minimizing COVID-19 spread (Canadian Patient Safety Institute 2011) (Health Canada 2020). With data analysis, delivery gaps must be detected and addressed, consequently making it easier for those who need catch-up to get caught up. Going forward, it will be important to:

- Recognize that no one size will fit all, but at the same time make efforts to decrease fragmentation of the immunization system.

- Adjust public health clinics and physician routine immunization times, and sites, to better meet patient needs.

- Make efforts to grow opportunities for routine immunization, such as standing orders for immunization when patients come in contact anywhere in the health system, e.g., visits to emergency rooms or clinics as well as admissions, for instance post splenectomy (Tahir et al. 2020).

Additionally, pharmacies can help if the types of immunizations and the age groups in their scope of practice are expanded. Finally, consider whether special catch-up clinics are 
needed and if so, how best to organize them in order to maximize attendance but minimize risk of COVID-19 transmission. Creativity and innovation are the watch words.

For all Canadian jurisdictions, the 2020/2021 fall school immunization programs will have overlapping cohorts as schools were closed in the spring of 2020 to mitigate COVID-19 spread. Plan now on how best to make the 2020/2021 immunization program effective, efficient and, to the degree possible, a positive experience for the students, teachers and the schools. Program revisions will vary by district as contexts differ. More resources will be needed due to the "double" cohort and additional measures required to limit potential COVID-19 transmission. Given the larger numbers of students, extra efforts are needed to mitigate student stress in order to minimize immunization stress-related responses (ISRRs) (Gold et al. 2020). Added stressors are in play; catching up on missed schooling in the previous spring, changed living with COVID-19 and the added pressure of more disinformation, including anti-vaccine rhetoric, ramped up with COVID-19 (https:/www.who.int/ docs/default-source/coronaviruse/situation-reports/20200202sitrep-13-ncov-v3.pdf ). Making the immunization experience as positive as possible is critical for program success. The CARD (Comfort, Ask, Relax, Distract) program has been shown to help (Taddio et al. 2019). Additionally, because school programs are "mass" campaigns, public health programs need to be prepared for potential crises if any serious adverse events occur - including clusters of ISRRs. Chapter 7 in the 2019 WHO report on Immunization Stress-related Responses outlines approaches (World Health Organization 2019).

Given the potential for further waves of COVID-19 that may occur concurrently with influenza this upcoming winter, access and uptake of influenza vaccine this fall must be optimized to help mitigate the health system capacity crunch if both viruses strike concurrently or overlap (National Advisory Committee on Immunization 2020). Given that influenza campaigns may be delivered in mass settings with stress levels increased if COVID-19 resurges, public health needs to be very prepared to address cases and/or clusters of adverse events following immunization. Not doing this well could undermine the whole immunization program.

Whether catch-up, routine, or mass immunization is being done, in all settings, steps need to be taken to minimize risk of acquisition of communicable infections, including COVID-19 (Canadian Patient Safety Institute 2011) (Health Canada 2020). Measures may differ by setting but must be adequate to allay concerns among healthcare workers and the public. Measures may include but are not limited to, appropriately timed appointments to minimize waiting, appropriate space in waiting rooms for physical distancing, use of personal protective equipment according to local guidance, and frequent, meticulous hand hygiene.

\section{Communicate, document, evaluate and readjust}

The COVID-19 pandemic is a stark reminder of how fast and how far a viral illness can travel when unchecked by a vaccine. Communicating why routine immunization, including for influenza, is so important now during this COVID-19 pandemic is critical to maximize uptake. However, given wave after wave of public health COVID-19 messages, be careful that routine immunization messages are not relegated to background noise. Concerns about immunization must be heard and addressed whether these are related to currently available vaccines or worries about COVID-19 vaccines to come. Public health leadership must be clearly seen. Communications must be tailored to fit the subgroup targeted - infants, young children, school-age children, pregnant women, seniors, those with underlying conditions, those who are up to date, and those now in need of catch-up all need to be considered. When messages are being developed, remember that risk perceptions influence behaviour but how risks are perceived may not reflect actual risk (van der Plight 1996). The scientific community, healthcare providers (doctors, nurses), and all public health actors must be able to send clear messages to the public on the value and importance of immunization, as the same evidence-based message from many sources can help shape beliefs (Gateway Belief Model) (van der Linden et al. 2015). They should utilize strategies that are known to help increase vaccine acceptance, including addressing hesitancy, at the program and at the patient levels (MacDonald et al. 2018a and 2018b). Garnering support from community leaders can be helpful in making vaccine acceptance across the life course the normative behaviour for self, family and community protection.

Program follow-up and evaluation are critical for success. Tracking who has been reached in the catch-up programs and who is still missing should influence further program adjustments. Questions to direct programs and efforts include:

- What is working and what gaps remain?

- Are subgroups missed?

- Are the vaccine messages being heard?

- What is the level of community support for immunization?

- Are vaccine or immunization program concerns being addressed?

Evaluating the impact of public health messaging is key to understanding how best to move forward. Monitoring, evaluation and readjustment require collaboration between public health, healthcare system workers, the media and community leaders. Speed is important. 


\section{Conclusion}

In summary, no one is safe from vaccine-preventable diseases until we are all safe. Catching up those who have missed routine immunization across the life course needs to be done quickly and effectively. This requires data, collaboration, innovation and community support. We must bear in mind that we cannot go back to a pre-COVID-19 world. However, ensuring that routine immunization and catch-up programs are done well during this pandemic strengthens the immunization foundation for when COVID-19 vaccines become available.

\section{References}

Abbas KM, Procter SR, van Zandvoort K, Clark A, Funk S, Mengistu T, Hogan D, Dansereau E, Jit M, Flashe S, LSHTM CMMID Covid-19 Working Group (2020) Benefit-risk analysis of health benefits of routine childhood immunisation against the excess risk of SARSCoV-2 infections during the Covid-19 pandemic in Africa. s.1. : LSHTM CMMID Repository.

Canadian Patient Safety Institute. (2011). Measures: infection prevention and control. Patient safety metrics. [Online] Canadian Patient Safety Institute. https://www.patientsafetyinstitute.ca/en/toolsResources/ psm/Pages/IPAC-measurement.aspx. Accessed 27 May 2020.

Edelstein, M., White, J., Bukasa, A., Saliba, V., \& Ramsay, M. (2019). Triangulation of measles vaccination data in the United Kingdom of Great Britain and Northern Ireland. Bulletin of the World Health Organization, 97(11), 754-763.

Gold, M. S., MacDonald, N. E., McMurtry, M. C., Balakrishnan, M. R., Heininger, U., Menning, L., Benes, O., Pless, R., \& Zuber, P. L. F. (2020). Immunization stress-related response - redefining immunization anxiety-related reaction as an adverse event following immunization. Vaccine, 38(14), 3015-3020.

Health Canada. (2020). Infection prevention and control for COVID-19: second interim guidance for acute healthcare settings. Health Canada, Government of Canada. [Online]. https://www.canada.ca/ en/public-health/services/diseases/2019-novel-coronavirusinfection/health-professionals/infection-prevention-control-covid19-second-interim-guidance.html. Accessed 27 May 2020.

MacDonald, N. E., Dube, E., \& Canadian Paediatric Society, Infectious Diseases and Immunization Committee. (2018a). Addressing vaccine hesitancy in immunization programs, clinics and practices.
Paediatrics \& Child Health, 23(8), 559. https://www.cps.ca/en/ documents/position/vaccine-hesitancy-in-immunization-programs.

MacDonald, N. E., Desai, S., Gerstein, B., \& Canadian Paediatric Society, Infectious Diseases and Immunization Committee. (2018b). Working with vaccine-hesitant parents: An update. Paediatrics \& Child Health, 23(8), 561. https://www.cps.ca/en/ documents/position/working-with-vaccine-hesitant-parents.

National Advisory Committee on Immunization. (2020). Interim guidance on continuity of immunization programs during the COVID19 pandemic. National Advisory Committee on Immunization (NACI): Statements and publications. [Online]. https://www. canada.ca/en/public-health/services/immunization/nationaladvisory-committee-on-immunization-naci/interim-guidanceimmunization-programs-during-covid-19-pandemic.html. Accessed 25 May 2020.

Santoli, J. M., Lindley, M. C., DeSilva, M. B., Kharbanda, E. O., Daley, M. F., Galloway, L., Gee, J., Glover, M., Herring, B., Kang, Y., Lucas, P., Noblit, C., Tropper, J., Vogt, T., \& Weintraub, E. (2020). Effects of the COVID-19 pandemic on routine pediatric vaccine ordering and administration - United States. MMWR. Morbidity and Mortality Weekly Report, 69(19), 591-593.

Taddio, A., McMurtry, C. M., Bucci, L. M., MacDonald, N., Ilersich, A. N. T., Ilersich, A. L. T., Alfieri-Maiolo, A., deVlaming-Kot, C., Alderman, L., \& Team. (2019). Overview of a Knowledge Translation (KT) project to improve the vaccination experience at school: the CARD ${ }^{\mathrm{TM}}$ System. Paediatrics \& Child Health, 24(Suppl 1), S3-S18.

Tahir, F., Ahmed, J., \& Malik, F. (2020). Post-splenectomy sepsis:a review of the literature. Cureus, 12(2), e6898.

van der Linden, S. L., Clarke, C. E., \& Maibach, E. W. (2015). Highlighting consensus among medical scientists increases public support for vaccines: evidence from a randomized experiment. Dec 2, 2015. BMC Public Health, 15, 1207.

van der Plight, J. (1996). Risk perception and self-protective behaviours. European Psychologist, 1, 34-43.

World Health Organization. (2019). Immunization stress-related responses. Geneva: World Health Organization.

World Health Organization. (2020). At least 80 million children under one at risk of diseases such as diphtheria, measles and polio as COVID-19 disrupts routine vaccination efforts, warn Gavi, WHO and UNICEF. [Online] World Health Organization. https://www. who.int/news-room/detail/22-05-2020-at-least-80-million-childrenunder-one-at-risk-of-diseases-such-as-diphtheria-measles-andpolio-as-covid-19-disrupts-routine-vaccination-efforts-warn-gaviwho-and-unicef. Accessed 27 May 2020.

Publisher's note Springer Nature remains neutral with regard to jurisdictional claims in published maps and institutional affiliations. 